\begin{abstract}
Harry Newman. Impressive Shakespeare: Identity, Authority and the Imprint in Shakespearean Drama. Material Readings in Early Modern Culture. New York: Routledge, 2019. Pp. xviii, 199. Hardback £105. ISBN: 1472465326. https://doi.org/10.4324/9781315588001
\end{abstract}

\title{
CLAIRE MCEACHERN
}

University of California Los Angeles

Shakespeare is that most elusive of authors, yet we continue to find his fingerprints everywhere in his work. In this detailed study Harry Newman delves into the deep material bedrock behind the notion of Shakespeare's ability to impress himself upon our imaginations. Providing a series of meticulous examinations both of the early modern technologies of impression - stamping, sealing, coining, and printing - and of their metaphoric registers in a number of the plays, Newman argues that Shakespeare's engagement with these technologies serves to 'interrogate the formation of identity and authority' (5), that of his own authorship foremost of all. As such, Newman views Shakespeare's embedding of the language of impressions as having the power to anticipate and shape his own critical reputation. Unlike many materialist studies, and despite providing a wealth of information about early modern practices of impression, Newman 'is concerned not so much with what Shakespeare's imprinting metaphors can tell us about the world in which he wrote, as ... about the texts in which they occur' (7), and hence his method is to proceed by means of intimately worked close readings of Coriolanus, A Midsummer Night's Dream, Measure for Measure, and The Winter's Tale. Newman also provides sustained reflection upon how the material becomes the figurative - how we make metaphors out of matter - and also the ways in which far from being considered an abstracting form in the rhetorical understanding of the period, metaphor was understood as a strenuously athletic wresting of signification designed to produce what he terms 'psychophysical' (6) transformations in their auditors.

Following an introduction that establishes how contemporaries considered the technologies of impression to be imbricated in each other, the book divides into a series of readings of the plays that examine concepts long used as metrics of Shakespearean exceptionality - character, rhetorical transformation, counterfeiting, and paratextual-paternal authority. Newman does not address whether there are other plays or poems in the canon which engage the language of impression (the book cries out for a discussion of Lucrece), or why, with the exception of Measure - written in the chronological vicinity of James I's accession and 
concomitant impression of himself on the country's coinage - the plays he chooses are so dedicated to this idiom; nevertheless, his evidence for the fact that they are so is overwhelming. There is a great deal to learn from this book when it comes to the material practices of impression, and individual essays make the case that Shakespeare was particularly taken with their lexicon.

The chapter on Coriolanus takes what is perhaps the hardest case of Shakespearean character to explore the links between wounding and imprinting as a means to understand the refusals of this character to appeal to our affections: 'Coriolanus' wounds are not so much signs of humanity as stamps with the technological capacity to deliver an impression of humanity' (64). Newman argues that the play's many metatheatrical devices encourage the audience to contemplate their own impressions and that by this means Shakespeare foregrounds his own aesthetic ambitions. His discussion of A Midsummer Night's Dream similarly finds the metaphors of wax sealing rife in the play, and that the play's 'self-reflexive language of figuration, disfiguration and transfiguration has the potential to shape audience's understanding and experience of poesis in the theatre, causing them to perceive it as impressive and transformative' (71). In the case of this play, Newman's research into the technology allows for a transformative reading of the play's gender politics, in which Hermia (and by extension all the play's women) is not merely impressionable matter to be transformed by the patriarchy, but selfpossessed: 'the implied "document" of Hermia's metaphor ... like the doublesided Great Seal ... communicates not passivity and subjugation, but the legitimate agency of a women who holds 'sovereignty' over her own body and soul' (85). In Measure for Measure we find Shakespeare similarly reflecting on his writing's status: it 'uses a numismatic motif to negotiate its value as a counterfeit or debased comedy' (102). This chapter also provocatively traces the ways in which scholarly discussions of Middleton's reworkings of parts of the play follow terms the play itself establishes: 'just as "moral purity" is ... an idea most apparent in the spiritual trials of Angelo and Isabella, notions of authorial purity are comparatively central to Shakespeare studies' (111). In the piece on The Winter's Tale, Newman daringly argues that the paratexts of the first folio become linked to that play through a linguistic register of printing as paternity, and so we find Shakespeare crafting the presentation of his work in book form in effect from beyond the grave. The study of gender is not merely a gallant gesture in Newman's work but a deeply considered and researched element of his understanding of literary affect and its designs upon our own memorial desires.

Newman's Shakespeare is a deeply ruminative writer, one seized by particular metaphorical conceits and returning to them over the course of a writing 
experience in order to explore various angles and implications of figure. While we are used to thinking of Shakespeare as reflecting upon his own writerly reputation in other contexts, such as the eternizing claims of the sonnets, Newman makes a convincing case for his studied contemplation of the value and force of his writing qua writing in dramatic contexts as well. (In fact, if Newman leaves a flank open in this study, it is in his frequent resort to the language of conjecture, which crops up most when it comes to his surmises about the effects on early modern audiences: 'likely', 'probably' [59]; 'might well have felt' [61]; 'may have invoked' [80]; 'may indeed gesture' [84].) Our continuing engagement with this most canonical of authors is, Newman argues, deeply cued, almost in a Pavlovian sense, by his linguistic textures. 
